8. GLM showed efficacy in DMARD-refractory AU (2nd line and further) and other biologic therapies (EL 3a; RG B-C).

Disclosure of Interest: None declared

DOI: 10.1136/annrheumdis-2017-eular.2626

\section{THU0550 TREATMENT AND OUTCOMES IN SPANISH PATIENTS WITH IGG4-RELATED DISEASE}

A. Fernández-Codina ${ }^{1}$, I. Pinal-Fernández ${ }^{2}$, B. Pinilla ${ }^{3}$, C. López ${ }^{4}$,

R. Solans-Laque ${ }^{1}$, G. Fraile-Rodríguez ${ }^{5}$, E. Fonseca-Aizpuru ${ }^{6}$,

J.M. Cameselle-Tejeiro ${ }^{7}$, S. Prieto-González ${ }^{8}$, J. Pardos-Gea ${ }^{1}$, J. Gil ${ }^{9}$,

T. Rossinyol ${ }^{10}$, M.J. Núñez-Fernández ${ }^{11}$, G. Salvador-Cervelló ${ }^{12}$,

F. Martínez-Valle ${ }^{1}$ on behalf of Spanish Registry of IgG4-related disease (REERIGG4). GEAS-SEMI. ' Systemic Autoimmune Diseases Unit, Hospital Universitari Vall d'Hebron, Barcelona, Spain; ${ }^{2}$ Muscle Disease Unit, National Institute of Arthritis and Musculoskeletal and Skin Diseases, Bethesda, United States; ${ }^{3}$ Internal Medicine, Hospital General Universitario Gregorio Marañón; ${ }^{4}$ Internal Medicine, Hospital General Gregorio Marañón; ${ }^{5}$ Internal Medicine, Hospital Ramón y Cajal, Madrid; 6 Internal Medicine, Hospital de Cabueñes, Gijón; ${ }^{7}$ Pathology, Hospital Clínico Universitario, Santiago de Compostela: ${ }^{8}$ Vasculitis Research Unit, Hospital Clinic i Provincial, Barcelona; ${ }^{9}$ Internal Medicine, Hospital Río Hortega, Valladolid: 10 Internal Medicine, Hospital de Manacor, Manacor; ${ }^{11}$ Internal Medicine, Complejo Hospitalario de Pontevedra, Pontevedra; ${ }^{12}$ Internal Medicine, Hospital la Fe, Valencia, Spain

Background: There is a lack of strong evidence on IgG4-related disease (IgG4$\mathrm{RD}$ ) treatment. There is only one clinical trial published, supporting the use of rituximab in American patients.

Objectives: To describe the treatments used in a series of patients diagnosed with IgG4-RD in Spain and to review the outcomes.

Methods: Clinical data were obtained from the Spanish Registry of IgG4-RD from October 2013 to January 2016, including 14 centers. Outcomes were assessed by a self-made response scale and the IgG4 responder index (RI). We categorized the outcomes as a total response (disappearance of the pseudotumoral lesions and absence of symptoms), partial response $(<50 \%$ regression of the tumefactive lesions or persistence of inflammation without symptoms) and no response if no changes were noticed. Treatment failure was considered if an increase of the activity, mass size or reappearance of symptoms were noticed among patients under treatment.

Results: Sixty-eight patients were included. Twenty-six (38\%) were females, mean age 53.4 years. Thirty-six patients $(52.9 \%)$ had systemic lgG4-RD involving $>1$ tissue. The most commonly involved tissues were: retroperitoneum (33\%), orbital pseudotumor $(28 \%)$, and maxillary and paranasal sinuses $(24 \%)$. The main treatments used were: steroids $(90 \%)$, surgery $(45 \%)$ and azathioprine $(19 \%)$. All treatments were successful in achieving complete or partial response. The mean pre and post-treatment RI values were 6.7 (SD 4.6) and 1.9 (SD 2.6) respectively. There were no differences between systemic and nonsystemic disease regarding the chosen treatments and the outcomes. The combination azathioprine-steroids was used in 12 patients. Fourteen percent of them relapsed (considering relapse as an increase of the inflammation, mass size or reappearance of symptoms, since the first month after the treatment withdrawal). The treatment failed in $28.6 \%$ of them. The combination steroidsrituximab was indicated in 6 patients, showing no relapses and 1 treatment failure. The majority of patients treated with azathioprine or rituximab combined with steroids had a systemic disease (6.6 and $80 \%$, respectively). Nearby all of them had already failed other previous treatments.

Conclusions: In our series, IgG4-RD has been treated with a myriad of drugs and procedures. The outcomes have been acceptable but the disease tended to relapse $(21 \%)$ and the treatment failures were common $(27 \%)$, probably due to the lack of well-defined treatment schemes supported by solid studies. Steroids were still the cornerstone of the treatment. Rituximab results were promising in our study but the number of patients was limited. Azathioprine, in combination with steroids, may be an accessible alternative treatment for IgG4-RD that should be explored. The RI correlated with the treatment outcomes and will have an important role monitoring future studies on IgG4-RD therapies.

Disclosure of Interest: None declared

DOI: 10.1136/annrheumdis-2017-eular.1135

\section{THU0551 ARTHRITIS IN SARCOIDOSIS - A MULTI-CENTRE STUDY FROM INDIA}

A. Jain, V. Agarwal on behalf of Arthritis in Sarcoidosis Group (A.S.G.): Jain A, Agarwal Vikas, Agarwal Vinita, Aggarwal A, Aggarwal P, Chowdhury AC, Ghosh P, Lawrence A, Misra DP, Misra R, Mohapatra M, Nath A, Negi VS, Pandya SC, Reddy VV, Prasad S, Shobha V, Singh YP, Tripathy SR, Wakhlu A. Clinical Immunology, SGPGIMS, Lucknow, India

Background: $10-15 \%$ of sarcoid patients have associated arthropathy. Chronic arthritis is less common varying from 1-2\% [1].Data on articular manifestations of the disease from India is sparse.[2]

Objectives: To study the clinical manifestations of sarcoid arthritis patients from India.

Methods: Case records of patients presenting to ten rheumatology centres from
2005 to 2016 with sarcoidosis were retrospectively reviewed. Joint involvement was assessed clinically, classified as acute or chronic depending on duration of symptoms lesser or greater than 6 months respectively.

Results: A total of 103 patients with sarcoid arthritis were reviewed. 58 patients were classified as Lofgren syndrome. Pattern of joint involvement revealed ankle as most commonly affected in both the groups (Table1). Wrist, MTP and PIP involvement was significantly more common in chronic sarcoid arthritis (table 1). Peripheral lymphadenopathy, plaques and uveitis were more frequent $(p<0.05)$ in chronic sarcoid arthritis $(50 \%, 20.8 \%, 25 \%$ respectively) compared to those with acute sarcoid arthritis (16.5\%,6.3\%,6.4\% respectively). 45 of 62 patients with acute arthritis with follow up details had achieved complete remission.15/24 patients with chronic sarcoid arthritis patients with a median follow up of 2 years had achieved complete remission with 14,11 and 5 patients on steroids, methotrexate and hydroxychloroquine respectively. One patient with concomitant interstitial lung disease had died due to lung infection.

Table 1. Clinical characteristics of patients with sarcoid arthritis from India

\begin{tabular}{|c|c|c|}
\hline & Acute, $n=79$ & Chronic, $n=24$ \\
\hline Age (years) & $40^{\dagger}(33.5 \text { TO } 51)^{\star \star}$ & $42.5^{\dagger}(35-55)^{* *}$ \\
\hline Male : Female & $0.9: 1$ & $1.7: 1$ \\
\hline Duration of Symptoms (years) & $0.25^{\dagger}(0.08 \text { to } 1.5)^{\star \star}$ & $0.72^{\dagger}(0.5 \text { to } 4)^{\star \star}$ \\
\hline Oligoarthritis ( $\leq 4$ joints) & $58(73.4)^{\star \#}$ & $12(50)^{*}$ \\
\hline Polyarthritis ( $\geq 5$ joints) & $19(24.1)^{\star}$ & $12(50)^{*}$ \\
\hline Ankle & $71(89.9)^{*}$ & $21(87.5)^{\star}$ \\
\hline Wrist & $22(27.8)^{*}$ & $16(66.7)^{\star \ddagger}$ \\
\hline MTP & $5(6.3)^{\star}$ & $5(20.8)^{\star \ddagger}$ \\
\hline PIP & $12(15.2)^{\star}$ & $9(37.5)^{\star \ddagger}$ \\
\hline Hilar/Mediastinal Lymphadenopathy & $66(83.5)^{*}$ & $21(87.5)^{\star}$ \\
\hline ILD & $23(29.1)^{*}$ & $12(50)^{\star}$ \\
\hline
\end{tabular}

${ }^{*}$ Percentage; ${ }^{\dagger}$ Median; ${ }^{*}$ IQR. ${ }^{\ddagger} p<0.05$. "One patient each had dactylitis and enthesitis as the only musculoskeletal manifestation.

Conclusions: Acute oligoarthritis was the commonest presentation with ankle most commonly affected joint. Wrist, PIP, MTP involvement were more common in chronic sarcoidosis. One of the limitation was retrospective analysis.

References:

[1] Ungprasert P, Crowson CS, Matteson EL. Clinical Characteristics of Sarcoid. Arthropathy: A Population-Based Study. Arthritis Care \& Research. 2016; 68(5):695-9.

[2] Govindarajan V, Agarwal V, Aggarwal A, Misra R. Arthritis in sarcoidosis. J. Assoc Physicians India. 2001;49:1145-7.

Disclosure of Interest: None declared

DOI: 10.1136/annrheumdis-2017-eular.5978

\section{THU0552 COMPLIANCE TO COLCHICINE TREATMENT IN FAMILIAL MEDITTERRANEAN FEVER RELATED AMYLOIDOSIS}

B. Yurttas ${ }^{1}$, S. Ugurlu ${ }^{2}, \mathrm{H}$. Ozdogan ${ }^{2} .{ }^{1}$ Department of Internal Medicine; ${ }^{2}$ Department of Internal Medicine, Division of Rheumatology, Istanbul University Cerrahpasa Medical Faculty, Istanbul, Turkey

Objectives: To assess the colchicine compliance in patients diagnosed with Familial Mediterrenean Fever (FMF) related amyloidosis in our center

Methods: Fourty one patients (18 male/23 female) were questioned with regards to colchicine compliance by using retrospective scanning of patient data.

Results: The mean age at the symptomatic onset of FMF was $7.13 \pm 5.24$ years. The mean age at the time of the FMF diagnosis was $21.21 \pm 14.85$ years. The mean age at the initiation of colchicine treatment was $21.42 \pm 14.75$ years and the mean age at time of the diagnosis of amyloidosis was found $29.57 \pm 12.14$ years. Mean duration of the disease was $31.702 \pm 11.84$ years and the duration of delayed diagnosis was $14.35 \pm 13.84$ years. Maximum dose of colchicine was $2,103 \pm 0,673$ $\mathrm{mg} /$ day. Compliance of colchicine treatment was poor in FMF related amyloidosis during their follow-up $(11 / 25, \% 44)$, rates of skipped doses were also high $(17 / 25$, $\% 68)$. Compliance rates were high in patients in whom FMF and amyloidosis were diagnosed simultaneously $(12 / 13, \% 93)$, rates of skipped doses were also low $(2 / 13, \% 14)$. One of the patients diagnosed with FMF after the diagnosis of amyloidosis was compliant, two of them were non-compliant; with regards to skipping doses, two patients were found to be compliant and therefore never skipped doses while one was skipping doses. The compliance to colchicine was high in all FMF patients once amyloidosis was evident $(31 / 41, \% 75)$, and rates of skipped doses were also low (12/41, \%30). In five FMF patients, amyloidosis was observed despite their compliance to treatment.

Conclusions: The overall delay of diagnosis in FMF patients with amyloidosis was found to be high. Particularly the FMF patients who were diagnosed with amyloidosis during their follow up were found to have lower rates of compliance. There were also a group of patients who were diagnosed with amyloidosis despite adequate and convenient colchicine treatment. It was emphasized that not only the early diagnosis and adequate treatment, but also the close follow up is important in managing FMF patients.

Disclosure of Interest: None declared

DOI: 10.1136/annrheumdis-2017-eular.5126 